\title{
APLIKASI PENDUKUNG KEPUTUSAN PENERIMAAN PEGAWAI DENGAN METODE SAW PADA PDAM TIRTA ASASTA
}

\author{
Arvia Meirita ${ }^{1}$, Dian Nur Sholihaningtias², Fery Rahmawan Asma ${ }^{3}$ \\ ${ }^{1}$ Program Studi Informatika. Universitas Indraprasta PGRI \\ Jl. Raya Tengah No.80, Kel Gedong, Kec. Pasar Rebo, Jakarta Timur \\ 1.
}

\begin{abstract}
ABSTRAK
Penerimaan pegawai pada PDAM Tirta Asasta Kota Depok masih belum berjalan dengan baik menyebabkan penumpukan data lamaran. Hal ini terjadi karena proses pengambilan keputusan tidak tepat sasaran dengan menggunakan satu kriteria. Tujuan penelitian ini adalah mengembangkan dan mengimplementasikan suatu sistem pendukung keputusan penerimaan pegawai menggunakan metode SAW (Simple Addictive Weighted) untuk mendapatkan alternatif terbaik yaitu pegawai baru. Metode pengembangan sistem, yaitu model waterfall. Dalam membangun sistem ini digunakan alat bantu perancangan sistem yaitu Flowchat serta dengan menggunakan bahasa pemrograman Java Netbeans dan penyimpanan data pada database MySQL menggunakan XAMPP. Hasil dari penelitian ini adalah membuat aplikasi pendukung keputusan penerimaan pegawai yang dapat mempermudah pekerjaan bagian SDM Kepegawaian dalam melakukan penilaian berdasarkan kriteria dan bobot yang sudah ditentukan agar mendapatkan hasil yang lebih efektif dan efisien pada PDAM Tirta Asasta Kota Depok.
\end{abstract}

Kata Kunci: Sistem Pendukung Keputusan, Pegawai, metode SAW, Java, Netbeans.

\section{ABSTRAK}

Recruitment of employees at PDAM Tirta Asasta Depok City is still not going well, causing the accumulation of application data. This happens because the decision-making process is not right on target using one criterion. The purpose of this study is to develop and implement a decision support system for hiring employees using the SAW (Simple Addictive Weighted) method to get the best alternative, namely new employees. System development method, namely the waterfall model. In building this system used system design tools, namely Flowchat and using the Java Netbeans programming language and data storage in the MySQL database using XAMPP. The result of this study is to make a decision support application for hiring employees that can facilitate the work of the Human Resources Department in conducting assessments based on predetermined criteria and weights in order to get more effective and efficient results at PDAM Tirta Asasta Depok City.

Key Word: Decision Support System, Employees, SAW method, Java, Netbeans.

\section{PENDAHULUAN}

"Perkembangan sistem dan teknologi komputer saat ini berkembang sangat pesat, besarnya kebutuhan informasi terhadap sistem pendukung keputusan". (Saputra, 2019) "Suatu perusahaan dapat berkembang dengan baik tentunya dipengaruhi oleh kualitas dan kompetensi pegawai". (Sayuti, 2017). "Persaingan pada industri usaha menjadikan perusahaan perlu meningkatkan sumber daya manusia yang berkualitas". (Hasibuan, 2017) Penerimaan pegawai pada PDAM Tirta Asasta Kota Depok masih belum berjalan dengan baik menyebabkan penumpukan data lamaran yang dilakukan secara manual, sering kali terjadi kesalahan dalam perhitungan skor setiap kriteria pengambilan keputusan tidak tepat sasaran. "Sistem pendukung keputusan merupakan proses pengambilan keputusan, pengolahan data dan informasi yang dilakukan bertujuan untuk menghasilkan berbagai alternatif keputusan yang dapat diambil". (Apriansyah, 2017) Metode Simple Additive Weighting (SAW) digunakan untuk memilih alternatif terbaik berdasarkan kriteria yang ditentukan, kemudian mencari nilai bobot dari setiap atribut, proses perangkingan untuk mendapatkan alternatif terbaik. "Metode Simple Additive Weighting (SAW) merupakan metode yang paling terkenal dan paling banyak digunakan dalam menghadapi situasi Multiple Attribute Decision Making (MADM)".(Yupianti \& Sari, 2017) "Multiple Attribute Decision Making (MADM) merupakan suatu metode pengambilan keputusan untuk menetapkan alternatif terbaik dari sejumlah alternatif berdasarkan beberapa kriteria tertentu". (Mailasari, 2016) Kriteria yang digunakan sebagai alat ukur untuk mengukur tingkat pencapaian tujuan. "Kriteria menunjukkan 
definisi dari suatu masalah dalam bentuk yang konkrit". (Budiarti, 2019) Flowchart merupakan penggambaran secara grafik dari langkah-langkah dan urutan prosedur suatu program. "Biasanya, mempengaruhi penyelesaian masalah yang khusunya perlu dipelajari dan dievaluasi”. (Indrajani, 2011) Berdasarkan hasil penelitian sebelumnya menggenai Aplikasi Pendukung Keputusan Penerimaan Pegawai di PDAM Tirta Asasta Kota Depok. Untuk itu dalam penelitian ini penulis menerapkan metode penelitian aplikasi pendukung keputusan menggunakan metode SAW (Simple Addictive Weighted) sebagai pembobotan dan kriteria. Dari hasil sistem yang dibangun membantu melakukan penilai secara lebih tepat karena didasarkan pada nilai kriteria dan pembobotan yang nantinya akan di jadikan perangkingan hasil untuk diterima atau tidak diterimanya menjadi pegawai baru.

\section{METODE PENELITIAN}

Dalam penelitian ini, peneliti menggunakan metode SAW (Simple Addictive Weighted) untuk menentukan penerimaan pegawai. Peneliti mempelajari sistem pendukung keputusan penerimaan pegawai pada PDAM Tirta Asasta Kota Depok mengenai masalah yang akan dipecahkan sehingga peneliti memperoleh data yang akurat. Metode pengembangan sistem yang digunakan pada aplikasi pendukung keputusan penerimaan pegawai dengan metode Simple Addictive Weighted (SAW), penulis menggunakan model waterfall. Metode waterfall adalah model klasik yang bersifat sistematis, berurutan dalam membangun software, disebut dengan waterfall karena, tahap demi tahap yang dilalui harus menunggu selesainya tahap sebelumnya dan berjalan berurutan (Lutfia, 2017).

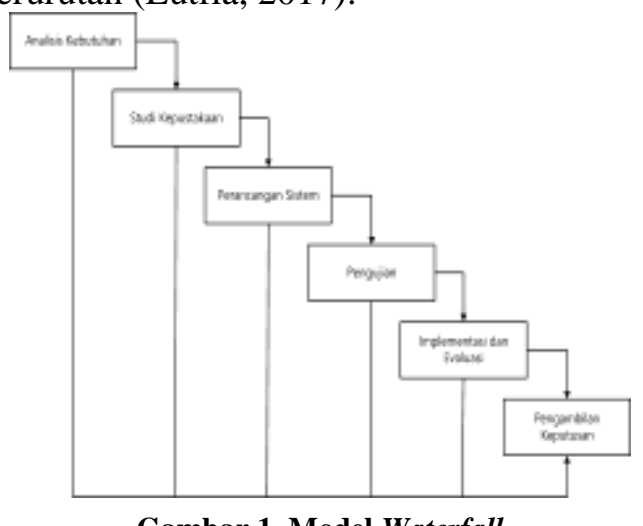

Gambar 1. Model Waterfall
Pengembangan sistem atau System Development Life Cycle (SDLC) adalah tahapan yang umum dilakukan dalam pembuatan atau perbaikan/pergantian sebuah sistem, dan mengacu juga pada metodologi yang digunakan untuk mengembangkan sistem informasi (Lisa, 2018). Sedangkan teknik pengumpulan data yang digunakan adalah wawancara, observasi dan metode kepustakaan.

\section{HASIL DAN PEMBAHASAN}

Langkah penyelesaian metode Simple Additive Weighting (SAW), dengan alat bantu perancangan sistem dengan flowchart adalah sebagai berikut:

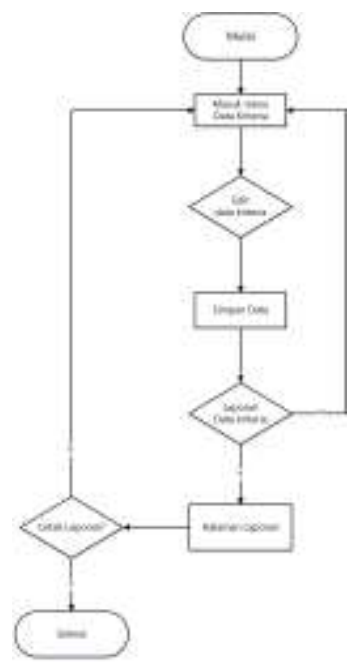

Gambar 2. Flowchart Data Kriteria

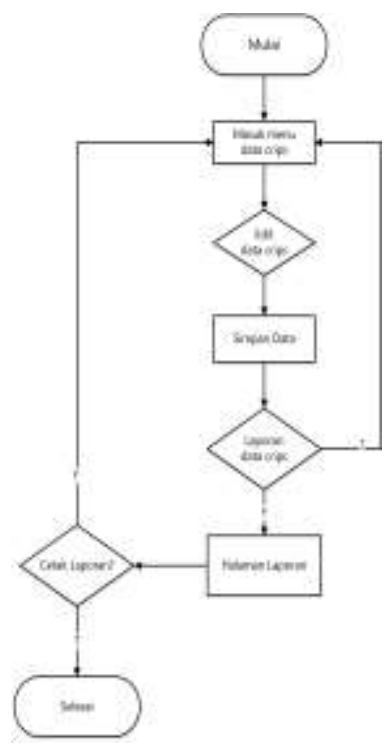

Gambar 3. Flowchart Data Crips 


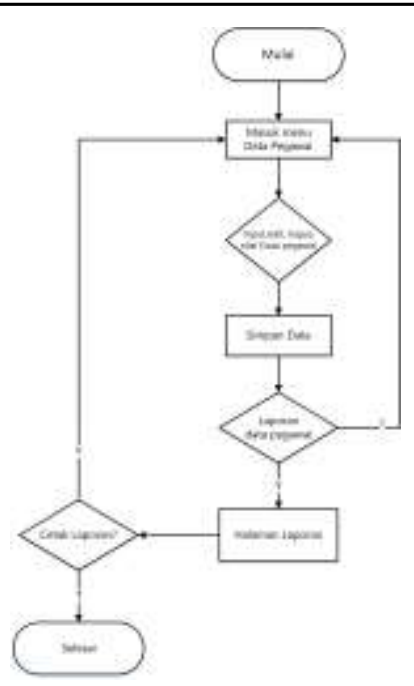

Gambar 4. Flowchart Data Pegawai

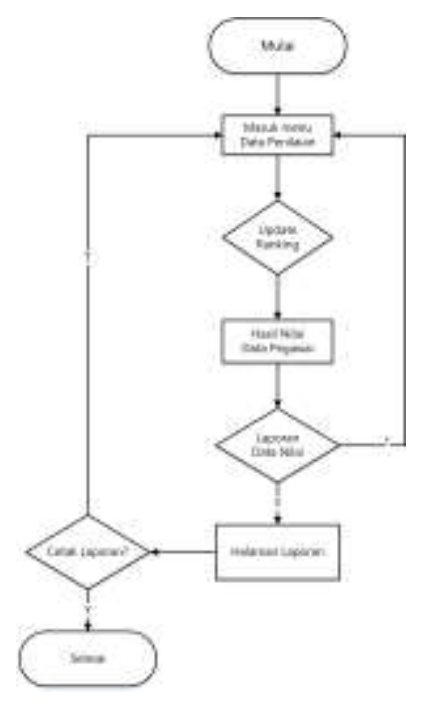

Gambar 5. Flowchart Data Nilai

Uji Coba Program dengan Contoh Data

Berikut ini adalah uji coba program dengan contoh data pada aplikasi pendukung keputusan penerimaan pegawai dengan metode SAW:

Tabel 1. Data Kriteria

\begin{tabular}{|c|c|c|c|}
\hline \multicolumn{4}{|c|}{ Tabel 1. Data Kriteria } \\
\hline Kode & Kriteria & Atribut & Bobot \\
\hline $\mathrm{C} 1$ & Tes Tertulis & benefit & 20 \\
\hline $\mathrm{C} 2$ & Psikotes & benefit & 20 \\
\hline $\mathrm{C} 3$ & Pendidikan & benefit & 20 \\
\hline $\mathrm{C} 4$ & IPK & benefit & 15 \\
\hline $\mathrm{C} 5$ & Pengalaman & benefit & 15 \\
\hline C6 & Domisili & cost & 10 \\
\hline & & Total & 100 \\
\hline
\end{tabular}

Pada data kriteria yang diperlukan dalam pengambilan keputusan penerimaan pegawai terdapat atribut benefit dan cost. Benefit merupakan kriteria yang mempunyai nilai besar, dan cost merupakan kriteria yang mempunyai nilai kecil.

Tabel 2. Penilaian Data Crips

\begin{tabular}{|l|c|}
\hline \multicolumn{1}{|c|}{ Penilaian } & Nilai \\
\hline Sangat Baik (81-100) & 100 \\
\hline Baik (61-80) & 80 \\
\hline Cukup (41-60) & 60 \\
\hline Rendah (21-40) & 40 \\
\hline Sangat Rendah (0-20) & 20 \\
\hline
\end{tabular}

Setiap crips memiliki bobot masing-masing kriteria penerimaan pegawai yang digunakan untuk perhitungan SAW dengan jumlah bobot terbaik menjadi acuan dalam perankingan penerimaan calon pegawai.

Tabel 3. Data Pegawai

\begin{tabular}{|l|c|c|c|c|c|c|}
\hline \multirow{2}{*}{\multicolumn{1}{|c|}{ Alternatif }} & \multicolumn{7}{|c|}{ Kriteria } \\
\cline { 2 - 8 } C1 & C2 & C3 & C4 & C5 & C6 \\
\hline Supirman Saputro & 20 & 40 & 60 & 80 & 100 & 50 \\
\hline Budi Setiawan & 80 & 60 & 80 & 60 & 60 & 50 \\
\hline Dewi Kusmawati & 80 & 60 & 80 & 80 & 60 & 80 \\
\hline Sigit Purnomo & 100 & 80 & 40 & 40 & 80 & 100 \\
\hline Wulan Aini & 60 & 100 & 40 & 60 & 40 & 50 \\
\hline Maharani Pratiwi & 40 & 20 & 60 & 40 & 40 & 100 \\
\hline MAX/MIN & 90 & 85 & 80 & 80 & 100 & 50 \\
\hline \multicolumn{7}{|c|}{} \\
\end{tabular}

Untuk melakukan normalisasi tabel ini, perlu memahami rumus berikut:

1. Rumus pada Atribut Benefit

$$
r_{i j}=\left\{\frac{x_{i j}}{\operatorname{Max} x_{i j}}\right.
$$

2. Rumus pada Atribut Cost

$$
r_{i j}=\left\{\frac{\operatorname{Min} x_{i j}}{x_{i j}}\right.
$$

Keterangan :

$$
\mathrm{Rij}=\underset{\text { Nilai rating kinerja }}{\text { ternormalisasi }}
$$


$\operatorname{Max}=$ Nilai terbesar dari setiap

Xij kriteria

Min = Nilai terkecil dari setiap

$\mathrm{Xij} \quad$ kriteria

$\mathrm{Xij}=$ Nilai atribut yang dimiliki setiap kriteria

\section{Perhitungan Normalisasi}

$X=\left[\begin{array}{cccccc}20 & 40 & 60 & 80 & 100 & 50 \\ 80 & 60 & 80 & 60 & 60 & 50 \\ 80 & 60 & 80 & 80 & 60 & 80 \\ 100 & 80 & 40 & 40 & 80 & 100 \\ 60 & 100 & 40 & 60 & 40 & 50 \\ 40 & 20 & 60 & 40 & 40 & 100\end{array}\right]$

$\mathrm{R} 11=\frac{20}{100}=0.2 \quad \mathrm{R} 41=\frac{80}{80}=1.0$

$\mathrm{R} 12=\frac{80}{100}=0.8 \quad \mathrm{R} 42=\frac{60}{80}=0.75$

$\mathrm{R} 13=\frac{80}{100}=0.8 \quad \mathrm{R} 43=\frac{80}{80}=1.0$

$\mathrm{R} 14=\frac{100}{100}=1.0 \quad \mathrm{R} 44=\frac{40}{80}=0.5$

$\mathrm{R} 15=\frac{60}{100}=0.6 \quad \mathrm{R} 45=\frac{60}{80}=0.75$

$\mathrm{R} 16=\frac{40}{100}=0.4 \quad \mathrm{R} 46=\frac{40}{80}=0.5$

$\mathrm{R} 21=\frac{40}{100}=0.4 \quad \mathrm{R} 51=\frac{100}{100}=1.0$

$\mathrm{R} 22=\frac{60}{100}=0.6 \quad \mathrm{R} 52=\frac{60}{100}=0.6$

$\mathrm{R} 23=\frac{60}{100}=0.6 \quad \mathrm{R} 53=\frac{60}{100}=0.6$

$\mathrm{R} 24=\frac{80}{100}=0.8 \quad \mathrm{R} 54=\frac{80}{100}=0.8$

$\mathrm{R} 25=\frac{100}{100}=1.0 \quad \mathrm{R} 55=\frac{40}{100}=0.4$

$\mathrm{R} 26=\frac{20}{100}=0.2 \quad \mathrm{R} 56=\frac{40}{100}=0.4$

$\mathrm{R} 31=\frac{60}{80}=0.75 \quad \mathrm{R} 61=\frac{50}{50}=1.0$

$\mathrm{R} 32=\frac{80}{80}=1.0 \quad \mathrm{R} 62=\frac{50}{50}=1.0$

$\mathrm{R} 33=\frac{80}{80}=1.0 \quad \mathrm{R} 63=\frac{80}{50}=0.625$

$\mathrm{R} 34=\frac{40}{80}=0.5 \quad \mathrm{R} 64=\frac{100}{50}=0.5$

$\mathrm{R} 35=\frac{40}{80}=0.5 \quad \mathrm{R} 65=\frac{50}{50}=1.0$

$\mathrm{R} 36=\frac{60}{80}=0.75 \quad \mathrm{R} 66=\frac{100}{50}=0.5$
Dimana rij adalah rating kinerja ternormalisasi dari alternatif pada atribut. Nilai preferensi untuk setiap alternatif $(\mathrm{Vi})$ menggunakan bobot yang telah ditentukan $\mathrm{W}=\{20 ; 20 ; 20 ; 15 ; 15 ; 10\}$. Hasil yang diperoleh sebagai berikut :

$$
V_{i}=\sum_{j=1}^{n} w_{j} r_{i j}
$$

Keterangan :

$\mathrm{V} i \quad=$ Nilai akhir dari setiap

$\mathrm{W} j \quad=$ Nilai bobot dari setiap rij $\quad=\begin{aligned} & \text { Nilai rating normalisasi } \\ & \text { matriks }\end{aligned}$

$\mathrm{V} 1=(0.2)(20)+(0.4)(20)+(0.75)(20)+$ $(1.0)(15)+(1.0)(15)+(1.0)(10)$

$=67.0$

$\mathrm{V} 2=(0.8)(20)+(0.6)(20)+(1.0)(20)+$ $(0.75)(15)+(0.6)(15)+(1.0)(10)$

$=78.25$

$\mathrm{V} 3=(0.8)(20)+(0.6)(20)+(1.0)(20)+$ $(1.0)(15)+(0.6)(15)+(0.625)(10)$

$=78.25$

$\mathrm{V} 4=(1.0)(20)+(0.8)(20)+(0.5)(20)+$ $(0.5)(15)+(0.8)(15)+(0.5)(10)$

$=70.5$

$\mathrm{V} 5=(0.6)(20)+(1.0)(20)+(0.5)(20)+$ $(0.75)(15)+(0.4)(15)+(1.0)(10)$

$=69.25$

V6 $=(0.4)(20)+(0.2)(20)+(0.75)(20)+$ $(0.5)(15)+(0.4)(15)+(0.5)(10)$

$=45.5$ 
Tabel 4. Nilai Ranking

\begin{tabular}{|c|l|c|c|c|}
\hline Ranking & Nama Pegawai & Nilai & Persentase & Keterangan \\
\hline 1 & Budi Setiawan & 78.25 & $78 \%$ & diterima \\
\hline 2 & Dewi Kusmawati & 78.25 & $78 \%$ & diterima \\
\hline 3 & Sigit Purnomo & 70.5 & $70 \%$ & diterima \\
\hline 4 & Wulan Aini & 69.25 & $69 \%$ & tidak diterima \\
\hline 5 & Supirman Saputro & 67.0 & $67 \%$ & tidak diterima \\
\hline 6 & Maharani Pratiwi & 45.5 & $46 \%$ & tidak diterima \\
\hline
\end{tabular}

Nilai Vi yang lebih besar mengindikasikan bahwa alternatif Ai lebih terpilih.

\section{Tampilan Progam}

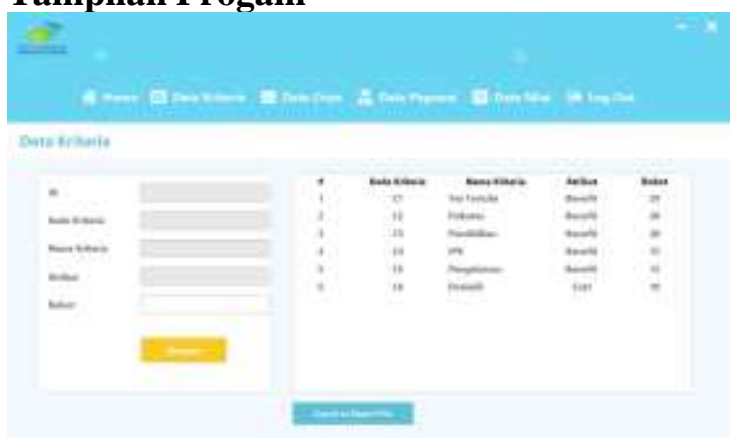

Gambar 6. Menu Data Kriteria

Tampilan Menu Data Kriteria pada tampilan menu ini, user dapat mengetahui informasi data nilai kriteria perusahaan pada tabel ini. Seperti, kode kriteria, nama kriteria, atribut dan nilai bobot.

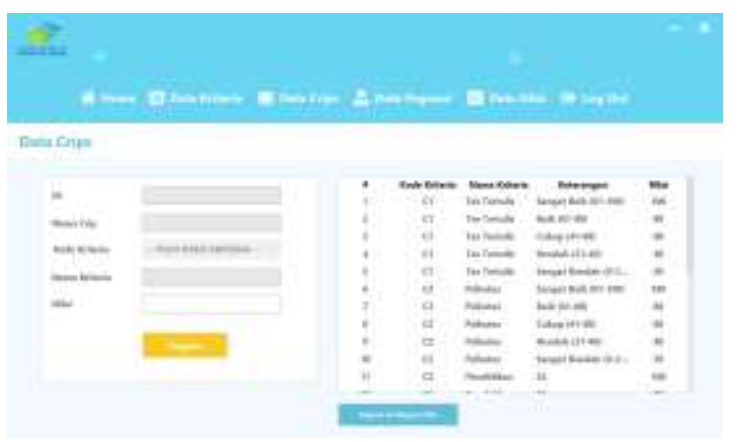

Gambar 7. Menu Data Crips

Tampilan Menu Data Crips (nilai kriteria) mengidentifikasikan kode kriteira, nama kriteria, keterangan, dan nilai bobot. Crips bersifat optional yaitu sebagai pembatas dari nilai setiap kriteria.

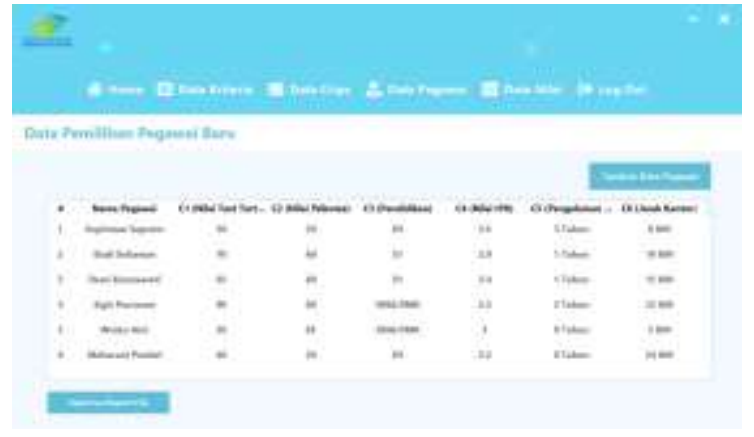

Gambar 8. Menu Data Pegawai

Tampilan Menu Data Pegawai merupakan alternatif yang akan dihitung nilainya dan dipilih sebagai alternatif terbaik.

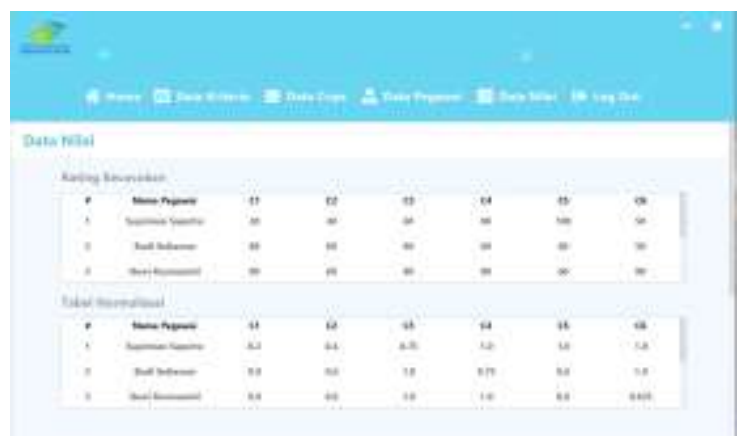

Gambar 9. Menu Data Nilai

Tampilan Menu Data Nilai ini mencatat nilai setiap alternatif berdasarkan semua data kriteria untuk melakukan perhitungan SAW.

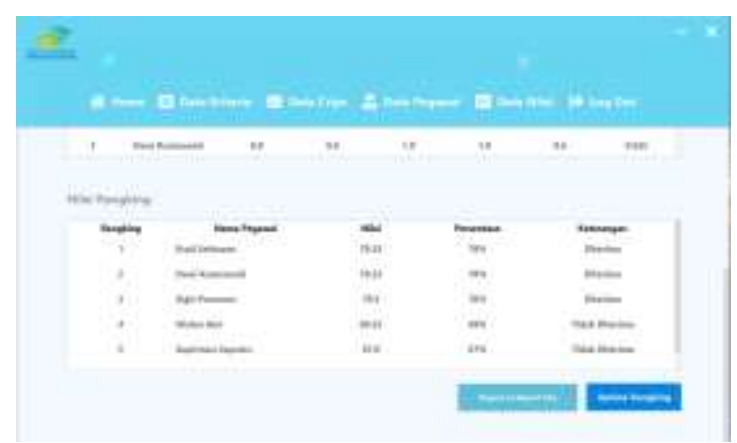

Gambar 10. Menu Nilai Ranking

Tampilan menu nilai ranking setiap calon 
pegawai yang telah diproses dengan metode SAW untuk diterima atau ditolaknya calon pegawai tersebut di perusahaan.

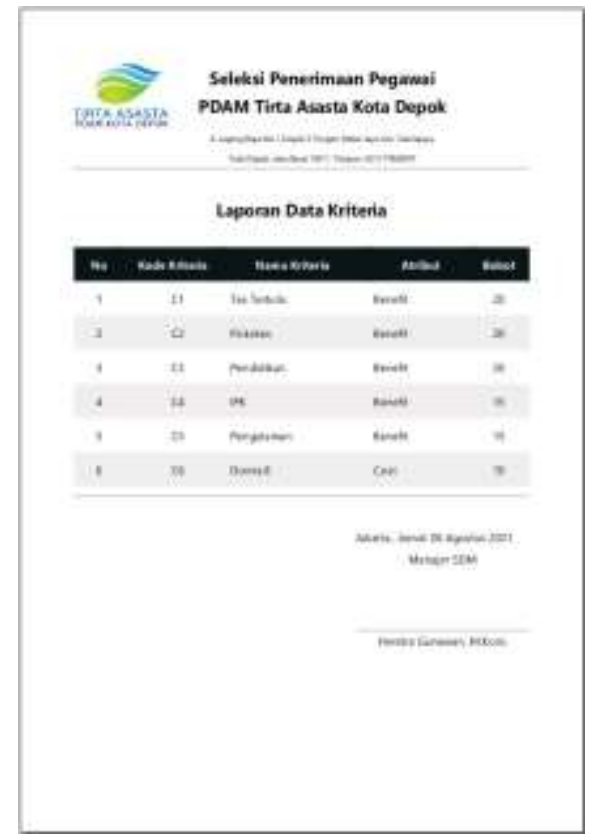

Gambar 11. Tampilan Laporan Data Kriteria

Tampilan ini berisikan laporan data kriteria yang terdiri dari kode kriteria, nama kriteria, atribut dan bobot setiap periode penerimaan calon pegawai. Untuk di review oleh bagian Manager SDM setiap bulannya.

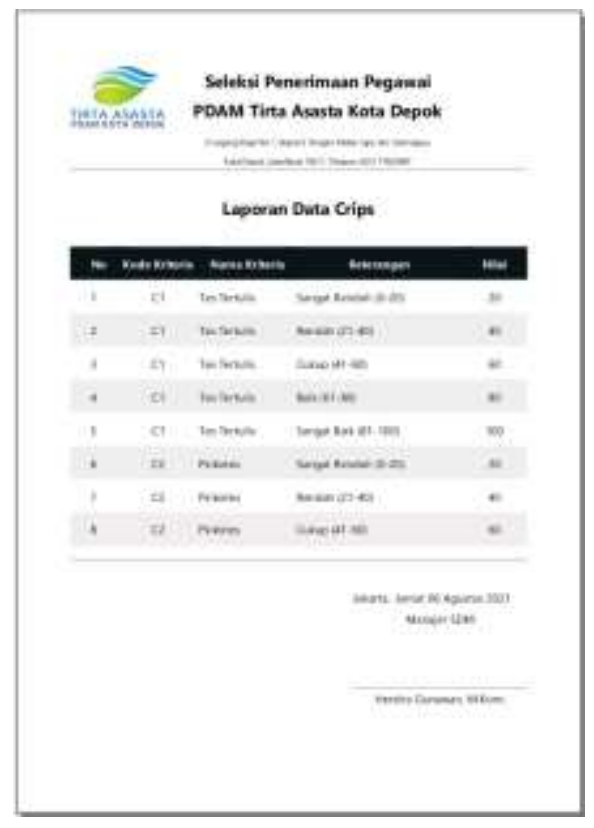

Gambar 12. Tampilan Laporan Data Crips

Tampilan ini berisikan laporan nilai data crips yang terdiri dari kode kriteria, nama kriteria, keterangan nilai, dan nilai setiap periode. Untuk di review oleh bagian Manager SDM setiap bulannya.

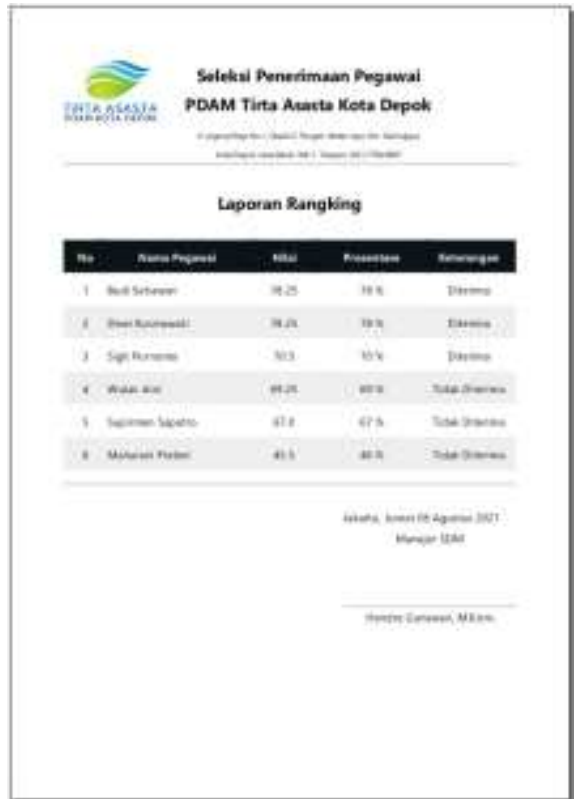

Gambar 13. Tampilan Laporan Data Ranking

Tampilan ini berisikan laporan nilai ranking yang terdiri dari nama pegawai, nilai, presentase dan keterangan setiap calon pegawai yang di terima atau di tolak. Untuk di review oleh bagian Manager SDM setiap bulannya.

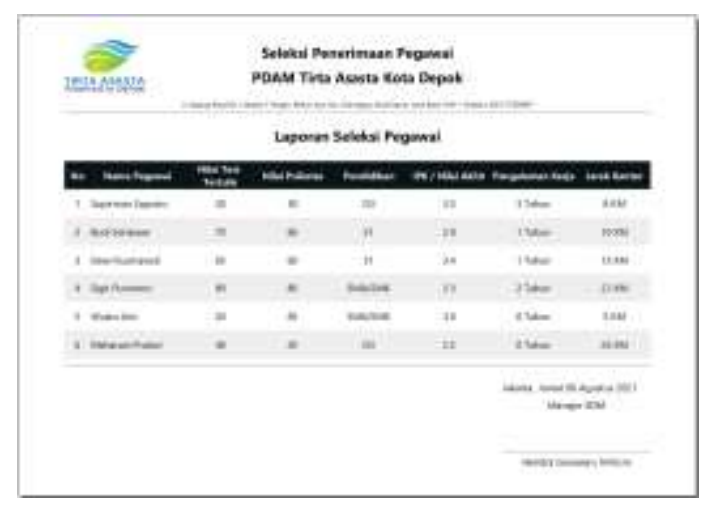

Gambar 14. Tampilan Laporan Data Pegawai

Tampilan ini berisikan laporan data penilaian calon pegawai yang terdiri dari nama pegawai, nilai test tertulis, nilai psikotes, pendidikan, IPK, pengalaman kerja dan jarak kantor dari setiap periode calon pegawai. Untuk di review oleh bagian Manager SDM setiap bulannya.

\section{SIMPULAN DAN SARAN}

Berdasarkan hasil pembahasan dari rumusan masalah pada Perancangan Aplikasi 
Pendukung Keputusan Seleksi Pegawai dengan Metode SAW pada PDAM Tirta Asasta Kota Depok, maka dapat disimpulkan, bahwa hasil analisis Sistem Aplikasi Pendukung Keputusan Seleksi Pegawai dengan menggunakan metode SAW dapat melakukan proses seleksi dengan tingkat akuratan $78 \%$, sehingga aplikasi ini dapat membantu SDM Kepegawaian di PDAM Tirta Asasta Kota Depok dalam mengambil keputusan seleksi penerimaan pegawai.

Berdasarkan penelitian dan analisis yang diusulkan oleh penulis, maka demi tercapainya tujuan yang diharapkan untuk penelitian selanjutnya dapat digunakan metode yang berbeda selain metode SAW sehingga menghasilkan sebuah sistem yang lebih baik.

\section{DAFTAR PUSTAKA}

Apriansyah, D. (2017). Sistem Pendukungkeputusan Seleksi Penerimapegawai Berprestasi Dengan Menggunakan Simple Additive Weighting ( Studi Kasuspada Kantor Kecamatan Kuningan ).

Budiarti, A. (2019). Kriteria Dan Analisis Multikriteria. Aplikasi Dan Analisis Literatur Fasilkom UI, 4-25.

Hasibuan. (2017). Pengertian Sumber Daya Manusia. Jurnal Teknik Informatika, $11-58$.

Indrajani. (2011). Pengertian Flowchart. It.Jurnal.Com, 5-22.

Lisa. (2018). System Development Life Cycle (SDLC). Paper Knowledge. Toward A Media History Of Documents, 7-32.

Lutfia, R. (2017). Aplikasi Pembagian Harta Waris Berbasis Android Dengan Metode Forward Chaining. Skripsi, 542.

Http://Eprinats.Uny.Ac.Id/53889/3/Ba b\%252.Pdf

Mailasari, M. (2016). Multiple Attribute Decision Making. II No 1(70), 100105.

Saputra, S. A. (2019). Sistem Pendukung Pengambilan Keputusan Penerimaan Pegawai Dengan Metode SAW. Journal Of Chemical Information And Modeling, 53(9), 1689-1699.

Sayuti. (2017). Pengertian Pegawai. 13-36.
Yupianti, Y., \& Sari, S. P. (2017). Sistem Pendukung Keputusan Penerimaan Karyawan Menggunakan Metode SAW (Studi Kasus Di PT. Nusantara Sakti Ciptadana Finance Kota Bengkulu). Jurnal Media Infotama, 13(2),55-66. Https://Doi.Org/10.37676/Jmi.V13i2.4 53 